\title{
Calculation on Bond Strength of High-Strength Concrete Filled Steel Tube
}

\author{
Xiao jun $\mathrm{Ke}^{1, \mathrm{a}^{*} \text {, Hai yang Sun }}{ }^{2, \mathrm{~b}}$ and Zhen Yang ${ }^{3, \mathrm{c}}$ \\ ${ }^{1}$ College of Civil Engineering and Architecture, Guangxi University, Nanning, China \\ ${ }^{2}$ College of Civil Engineering and Architecture, Guangxi University, Nanning, China \\ ${ }^{3}$ College of Civil Engineering and Architecture, Guangxi University, Nanning, China

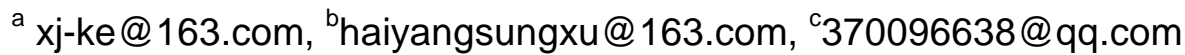

Keywords: concrete filled steel tube; high-strength concrete; push-out test; bond strength; slip Abstract. This paper describes a test study of the interface mechanical behavior of high-strength concrete filled steel tube. According to push-out tests of four specimens of high-strength concrete filled steel tube, the failure pattern and load-slip curves were analyzed. Test results show that the load-slip curves at the load end and free end are both a similarity for the stress-strain curves of steel with no apparent yield point. A reasonable calculation method for predicting the bond strength of high-strength concrete filled steel tube is presented based on the related theories and test results.

\section{Introduction}

With the improvement of concrete strength grade, the brittleness and deformation ability of high strength concrete reduces, which can affect the application scope in civil engineering. Thus, the concept of high-strength concrete filled steel tube is put forward, which is used in the lateral restraint of steel tube to overcome the brittleness of high strength concrete.

Several investigations by Cai (2003), Zhang (2004), Ellobody (2005), Zhong (2006), Han (2007), Li (2009), Hoang (2011), Ke (2014), et al. have been performed to quantify the mechanical properties and bearing capacity of high-strength concrete filled steel tube at home and abroad. Some researches by Cai (2003), Yang (2006), Kang (2008), Gourley (2008), Xu(2013), et al. have been carried on the calculation of bond strength between steel and normal or recycled aggregate concrete. However, few studies were done on the interface bond properties and bond strength of high-strength concrete filled steel tube. Up till now, the bond strength calculation theory was established by the basis of normal strength concrete filled steel tube mostly, and this theory verified by more tests. Therefore, this paper designed four specimens of high-strength concrete filled steel tube for push-out test. It can be help for theoretical analysis, numerical simulation and application of high-strength concrete filled steel tube

\section{Summary of Test}

\section{Design and Manufacture of Specimens.}

Four specimens of high-strength concrete filled steel tube, considered the mainly parameters of concrete strength and steel tube bond length, were designed for push-out test to reveal the interface mechanical behavior between steel tube and high-strength concrete. The design parameters of specimens are shown in Table 1.

Table 1 Design parameters of specimens.

\begin{tabular}{llllll}
\hline Labels & concrete strength & $L / \mathrm{mm}$ & $d / \mathrm{mm}$ & $t / \mathrm{mm}$ & $L_{\mathrm{e}} / \mathrm{mm}$ \\
\hline CST-1 & C60 & 430 & 110 & 3 & 400 \\
CST-2 & C70 & 430 & 110 & 3 & 400 \\
CST-3 & C80 & 430 & 110 & 3 & 400 \\
CST-4 & C70 & 330 & 110 & 3 & 300 \\
\hline
\end{tabular}

Notes: $L$ is specimen length; $d$ is the diameter of steel tube; $t$ is the thickness of steel tube; $L_{\mathrm{e}}$ is bond length of steel tube.

High strength concrete was supplied by a commercial ready-mixed plant, i.e. $42.5 \mathrm{R}$ brand ordinary Portland cement, sand, gravels with continuous gradation whose particle size ranged from $5 \mathrm{~mm}$ to 20 $\mathrm{mm}$, tap water and AF-C poly hydroxy acid high efficiency water reducing agent. The design mix 
proportion and concrete cube compressive strength $\left(f_{\text {cu }}\right)$ measured by Chinese Standard are shown in Table 2.

Circle steel tube use the straight welded steel tube with a diameter of $110 \mathrm{~mm}$. The yield strength $\left(f_{\mathrm{y}}\right)$, ultimate tensile strength $\left(f_{\mathrm{u}}\right)$ and elastic modulus $\left(E_{\mathrm{s}}\right)$ are $398 \mathrm{MPa}, 458 \mathrm{MPa}$, and $1.976 \times 10^{5} \mathrm{MPa}$ respectively.

All empty steel tubes were accurately cut to the required length, and the bottom of steel tubes was sealed with plastic film for avoiding the leakage of any slurry. $30 \mathrm{~mm}$ distance without pouring concrete on the top of steel tubes was reserved to control bond length during pouring concrete. All specimens were vibrated by a vibration table, and placed indoor to 28 days' natural curing after pouring concrete.

Table 2 Design mix proportion and performance index of concrete.

\begin{tabular}{lllllllll}
\hline \multirow{2}{*}{ concrete strength } & \multicolumn{2}{c}{ Material $/(\mathrm{kg} . \mathrm{m}-3)$} & \multicolumn{2}{c}{ slag $/ \%$} & silica fume $/ \%$ & \multicolumn{2}{c}{ water reducing } \\
& cement & Sand & gravel & water & & $f_{\text {cu }} / \mathrm{MPa}$ \\
\hline C60 & 408 & 576 & 1283 & 163 & 15 & 10 & 1.0 & 70.52 \\
C70 & 482 & 664 & 1097 & 160 & 15 & 10 & 1.5 & 75.01 \\
C80 & 533 & 745 & 1117 & 160 & 15 & 10 & 1.5 & 79.44 \\
\hline
\end{tabular}

\section{Test Loading and the Arrangement of Measuring Points}

All specimens were performed on RMT-201 rocked and concrete compression machine, produced by Institute of Rock and Soil Mechanics Chinese Academic of Science and SIMENS Company. Test set-up is shown as in Figure1. In this test, It should be need that a $30 \mathrm{~mm}$ thickness steel plate, whose diameter is slightly smaller than the inner diameter of steel tube, was putted on the load end to ensure that loading can be transfer from core concrete to steel tube, and make the bond failure. Three dial indicators were distributed on the load end and free end to measure the relative slip between steel tube and core concrete.

Loading was conducted by displacement, and the displacement speed was $0.002 \mathrm{~mm} / \mathrm{s}$. When the slip value at the load end was about $6 \mathrm{~mm}$, loading stopped.

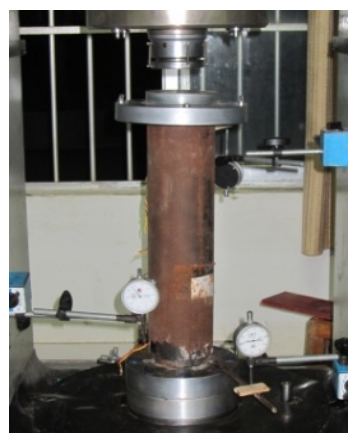

Figure 1 Test set-up

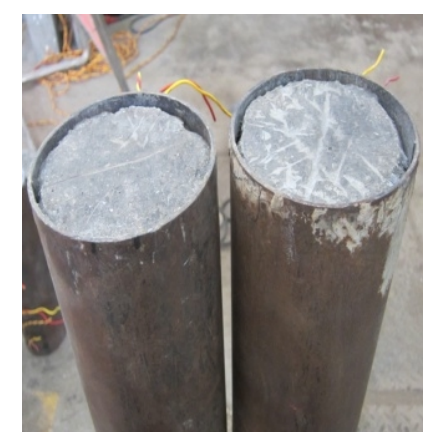

Figure 2 Failure pattern

\section{Test Results and Analysis.}

\section{Failure Pattern}

When loading to a certain load, it appeared a tiny slip at the load end, accompanying with slight noise. The noise may be released from the chemical bond force failure between steel tube and concrete. With the increasing of loading, the slip value at the load end increased continuously, and the noise became frequently. Before bond failure, a small amount of concrete debris fell off at the load end, and steel tube did not appear bending failure. The typical failure pattern is shown in Figure 2.

\section{Load-slip Curve}

The load-slip curves at the load end and free end are shown in Fig.3. It can be seen that the curve shape of all specimens is similar to the stress-strain curves of steel with no obvious yield point, and it generally posses the following characteristics:

a) The interface slip between steel tube and concrete can be divided into no slip, local slip and whole slid, which is a process of damage accumulation gradually.

b) The slip at the load end is the very early appearing, that is, the development of interface bond failure is from load end to free end. 
c) After the peak load, the load-slip curve falls slowly, and the bearing capacity is more stable with the increasing of concrete strength and steel tube bond length.

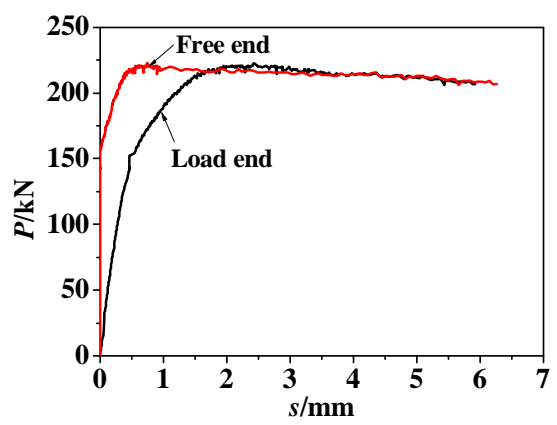

(a) Specimen CST-1

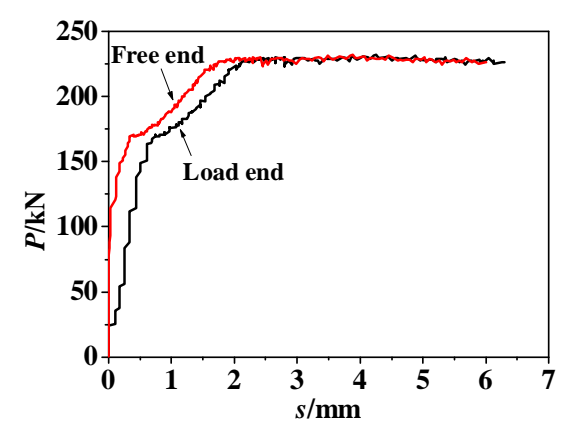

(c) Specimen CST-3

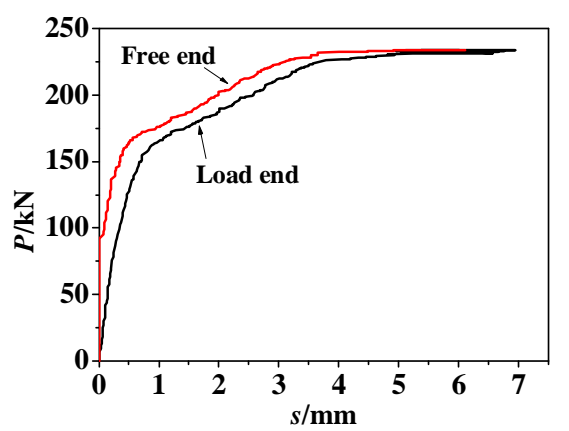

(b) Specimen CST-2

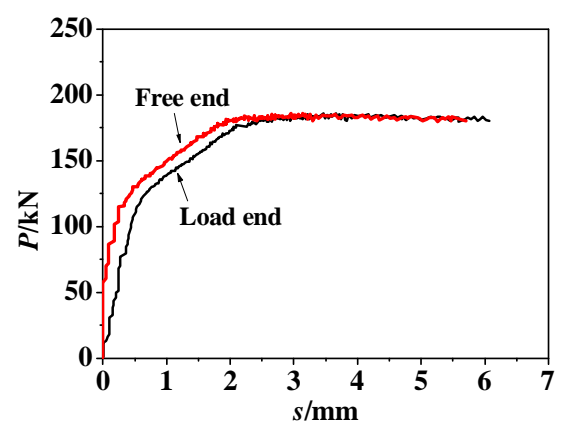

(d) Specimen CST-4

\section{Nominal bond strength}

Figure 3 Load-slip curves $(P-s)$

On the basis of the assumption that the bond stress is evenly distributed along the interface between steel tube and concrete, the measured nominal bond strength of concrete filled steel tube can be calculated by using Equation 1.

$$
\tau_{u}=\frac{P_{u}}{A}
$$

Where $\tau_{\mathrm{u}}$ is nominal bond strength; $P_{\mathrm{u}}$ is the bond failure load corresponding to the peak point or inflection point of load-slip curve; $A$ is the effective contact area between steel tube and concrete. Table 3 shows the measured nominal bond strength of all specimens. It can be seen that the bond strength improves with the increasing of concrete strength and steel tube bond length on the whole.

\section{Calculation Method of Bond Strength}

On the basis of further researches about the interface bond performance of normal or recycled aggregate concrete filled steel tube at home and abroad, different methods for calculating bond strength between steel tube and concrete were put forward. To verify whether the existing theories are suitable for high-strength concrete filled steel tube, several practical calculation methods are discussed in this paper.

\section{Calculation Method by Cai Shaohuai}

A typical calculation formula for bond strength of concrete filled steel tube in China, applied to concrete strength grade ranging from $\mathrm{C} 40$ to $\mathrm{C} 80$, is proposed by Cai Shaohuai.

$$
\tau_{\mathrm{u}}=0.1 f_{\mathrm{cu}}^{0.4}
$$

Where $f_{\text {cu }}$ is the cubic compressive strength of concrete

\section{Calculation Method by Kang Xiliang}

Through the regressive analysis of experimental data, Kang Xiliang put forward a calculation formula for bond strength of concrete filled steel tube, shown as follows.

$$
\tau_{\mathrm{u}}=\frac{1}{\gamma} k f_{\mathrm{t}}\left[-0.00028\left(4 L_{\mathrm{e}} / d\right)+0.11121 d / t+29.09049 \alpha+0.03439 \theta-7.36037\right]
$$


Where: $\gamma$ is the correction coefficient with the influence of uncertain factors, and $\gamma=0.96$ is suggested; $f_{\mathrm{t}}$ is the tensile strength of concrete; $k$ is the influence coefficient of steel tube's surface condition, and $k=1.3$ is suggested without rust; $\theta$ is the confinement coefficient $\left(\theta=\alpha f_{\mathrm{y}} / f_{\mathrm{c}}\right)$, in which the ratio of steel tube $\alpha=A_{\mathrm{s}} / A_{\mathrm{c}}, f_{\mathrm{y}}$ is the yield strength of steel tube, $f_{\mathrm{c}}$ is the axial compressive strength of concrete, $A_{\mathrm{s}}, A_{\mathrm{c}}$ are the area of steel tube and concrete, respectively.

\section{Calculation Method by Gourley}

Gourley holds that the diameter-thick ratio is the key factor which influences the bond strength of concrete filled steel tube, and it should be considered for calculating bond strength of concrete filled steel tube. According to the regressive analysis of test results, the bond strength between concrete and steel tube can be calculated by using Equation 5.

$$
\tau_{\mathrm{u}}=2.109-0.026(d / t)
$$

Where: $d$ is the outer diameter of steel tube; $t$ is the wall thickness of steel tube.

\section{Calculation Method by Chen Zongping}

On the basic of push-out test, Chen Zongping proposes the following calculation formula, which can consider simultaneously the influence of replacement rate of recycled coarse aggregate, concrete strength grade and length-diameter of ratio on bond strength of recycled aggregate concrete filled steel tube.

$$
\tau_{\mathrm{u}}=\left[0.0336+0.0141 \delta-0.0028\left(L_{\mathrm{e}} / d\right)\right] f_{\mathrm{cu}}
$$

Where: $\delta$ is the replacement rate of recycled coarse aggregate; $L_{\mathrm{e}} / d$ is the length-diameter ratio.

Predicted bond strength of high-strength concrete filled steel tube using different methods is compared with test results $\left(\tau_{\mathrm{u}}\right)$ in Table 3 . Results in Table 4 show that bond strength calculated by Equation 3 is about 1/3 of test results, and calculation results by Equation 4 and 5 are about 2/3 of test results. Therefore, the first three calculation methods are conservative for predicted bond strength, and give a safe prediction. The results calculated by Equation 6 are in a good agreement with test results, and the mean value of their ratio is 1.0. This represents that the calculation method proposed by Chen is the best predictor to predict the bond strength of high-strength concrete filled steel tube.

Table 3 Bond strength calculated by different calculation methods.

\begin{tabular}{ccccccccccc}
\hline Labels & $P_{\mathrm{u}} / \mathrm{kN}$ & $\begin{array}{c}\tau_{\mathrm{u}} \\
\end{array}$ & $\tau_{\mathrm{uPa} .2} / \mathrm{MPa}$ & $\tau_{\mathrm{u} .2} / \tau_{\mathrm{u}}$ & $\tau_{\mathrm{u} .3} / \mathrm{MPa}$ & $\tau_{\mathrm{u} 3} / \tau_{\mathrm{u}}$ & $\tau_{\mathrm{u} .4} / \mathrm{MPa}$ & $\tau_{\mathrm{u} .4} / \tau_{\mathrm{u}}$ & $\tau_{\mathrm{u} .5} / \mathrm{MPa}$ & $\tau_{\mathrm{u} 5} / \tau_{\mathrm{u}}$ \\
\hline CST-1 & 220.31 & 1.69 & 0.55 & 0.33 & 1.22 & 0.72 & 1.16 & 0.69 & 1.65 & 0.98 \\
CST-2 & 240.34 & 1.84 & 0.56 & 0.31 & 1.26 & 0.68 & 1.16 & 0.63 & 1.76 & 0.95 \\
CST-3 & 235.46 & 1.80 & 0.58 & 0.32 & 1.30 & 0.72 & 1.16 & 0.64 & 1.86 & 1.03 \\
CST-4 & 183.98 & 1.88 & 0.56 & 0.30 & 1.26 & 0.67 & 1.16 & 0.62 & 1.95 & 1.04 \\
\hline
\end{tabular}

Notes: $\tau_{\mathrm{u}}$ is the measured nominal bond strength; $\tau_{\mathrm{u} .2}, \tau_{\mathrm{u} .3}, \tau_{\mathrm{u} 4}, \tau_{\mathrm{u} .5}$ are corresponding to the results calculated by the Equation 2 5.

\section{Summary}

1) The load-slip curves at the load end and free end are both similar to the stress-strain curves of steel with no obvious yield point, the slip at the load end is the very early appearing.

2) The bond strength of high-strength concrete filled steel tube improves with the increasing of concrete strength and steel tube bond length on the whole.

3) Comparing with the specification regulated data, the measured bond strength is far greater. According to the existing theories, a reasonable calculation method is put forward to predict the interface bond strength of high-strength concrete filled steel tube.

\section{Acknowledgments}

The research reported in the paper is part of a research program supported by National Natural Science Foundation of China (No.51508112) and Guangxi Natural Science Foundation (No.2015GXNSFBA139210). 


\section{References}

[1] AIJ. 1997. Recommendations for design and construction of concrete filled steel tubular structures. Architectural Institute of Japan, Tokyo, Japan.

[2] Cai, S.H. 2003. Modern concrete filled steel tube structure. Beijing: People's Communications Press (in Chinese).

[3] Ellobody, E., Young, B. \& Lam, D. 2005. Behaviour of normal and high strength concrete-filled compact steel tube circular stub columns [J]. Journal of Constructional Steel Research, 62(7):706-715. [4] Han, L.H. \& Yang, Y.F. 2007. Modern technology of concrete filled steel tube structure. Beijing: China Building Industry Press (in Chinese).

[5] Hoang, V. L. \& Demonceau J.F. 2011. Field of application of high strength steel circular tubes for steel and composite columns from an economic point of view [J]. Journal of Constructional Steel Research, 67(6):1001-1021.

[6] Kang, X.L. 2008. Study on compositing mechanical performance and bond slip performance of concrete filled steel tube. Xi' an: Xi' an University of Architecture and Technology, (in Chinese).

[7] Ke, X.J., Chen, Z.P., Ying, W.D. \& Xue, J.Y. 2014. Experimental study on the behavior of high-strength concrete filled steel tube columns under axial compression loading. Building Structures, 44(16):46-49. (in Chinese).

[8] Li, B., Ma, K.Z. \& Liu, H.D. 2009. Experimental study on the seismic behavior of high-strength concrete filled steel tube columns. Engineering Mechanics, S1:139-143 (in Chinese).

[9] Gourley, B.C., Tort, C. \& Hajjar, J.F. 2008. A synopsis of studies of the monotonic and cyclic behavior of concrete-filled steel tube beam columns: structural engineering report. Urbana, Illinois: Department of Civil and Environmental Engineering, University of Illinois at Urbana Champaign, 179-180.

[10] Xu, J.J., Chen, Z.P., Xue J.Y.\& Su, Y.S. 2013. Failure mechanism of interface bond behavior between circular steel tube and recycled aggregate concrete by push-out test. Journal of Building Structures, 34(7):149-157.(in Chinese).

[11] Yang, Y.F. \& Han, L.H. 2006. Research on bond behavior between steel and concrete of self-compacting concrete filled steel tubes with rectangular sections. Industrial Construction, 36(11):32-36.(in Chinese)

[12] Zhang, S.M, Guo, L.H. \& Wang, Y.Y. 2004. Experimental research and theoretical analysis of high-strength concrete square hollow section steel tubes subjected to eccentric loading. Journal of Building Structures, 25(1):17-24+70. (in Chinese).

[13]Zhang, S.M, \& Wang, Y.Y. 2004. Failure modes of short columns of high-strength concrete steel tubes [J]. Chian Civil Engineering Journal, 37(9):1-10. (in Chinese).

[12] Zhong, S.T. 2006. Unified theory of concrete filled steel tube: theory and application. Beijing: Tsinghua University Press (in Chinese). 